\title{
Peak Expiratory Flow Rate in Respect to Anthropometric Parameters of Adolescent Boys and Girls from West Bengal, India
}

\author{
${ }^{1}$ Purushottam Pramanik*, ${ }^{2}$ Debasis koley, ${ }^{3}$ Indranarayan Ganguli \\ ${ }^{1,2,3}$ Post Graduate Department of Physiology, Hooghly Mohsin college, Chinsurah, Hooghly, west Bengal, India
}

\begin{abstract}
Peak expiratory flow rate (PEFR) is an essential measure in the management and evaluation of asthmatic children. Lung function parameters show wide variations with respect to geographical, climatic, anthropometric and socioeconomic condition are well known. The aim of this study was to determine normal PEFR of adolescent boys and girls of West Bengal state in Eastern India and to derive prediction formula for this population. The PEFR was measured in 1288 healthy school students ( 767 boys and 521 girls) of Hooghly district using the mini Wright's peak flow meter. All measurements were recorded in standing posture and resting condition. Best out of the three trials was recorded. Weight and height were measured. BMI and BSA were calculated using height and weight. Correlation between various anthropometric variables and PEFR were calculated. Positive correlation was seen between PEFR and age, height, weight, BMI and BSA Simple and multiple regression analysis were used to determine the influence of anthropometric variables on PEFR. Highest correlation was seen with age for boys and girls. The boys had higher PEFR than girls in respect to height and age. Simple regression equations were predicted on the basis of age, height, weight and BSA for boys and girls. Multiple regression equations were predicted on the basis of two anthropometric variables having higher correlation coefficient with PEFR. Equations derived from this study for estimation of expected PEFR values would help the clinician in assessing the airway obstruction in adolescent boys and girls of Eastern India.
\end{abstract}

Key words: PEFR, adolescent, age, height, weight, BSA

\section{Introduction}

Pulmonary function test (PFT) is an invaluable tool for the assessment of lung function. It is well known that pulmonary functions may vary according to physical characteristics including age, height, weight etc. and altitude. Significant regional differences in lung function in healthy Indian have been reported (1). PEFR is one such parameter that can be easily measured and is a convenient tool to measure lung functions in the field study (2). Its measurement does not require body temperature pressure saturated (BTPS) correction (1). PEFR as a measurement of ventilatory function was introduced by Hadron in 1942, and was accepted in 1949 as an index in spirometry (3). It is a simple reliable way to following up children with bronchial asthma and other obstructive lung diseases (4). It is a fairly good indicator of bronchial hyperresponsivness (5).The prevalence of pulmonary diseases especially bronchial asthma has been increased world wide (6). It has been recommended that PEFR should be a part of the diagnostic evaluation and treatment of asthma (7). Thus the measurement of PEFR will be useful to screen and monitor the severity of asthma in the community, particularly when the prevalence of asthma-related hospital admissions are rising (8). The peak flow meter, a small, portable, convenient and inexpensive device is useful instrument for monitoring PEFR in children and adults.

Pulmonary function is known to vary considerably between different regional and ethnic groups, residing within the same country (9). India, being a subcontinent, changes in pulmonary function can occur from one region to another $(10,11)$. Therefore, reference standard for each ethnic group of region for better evaluation of pulmonary function is very essential.

Adolescent age group varies from 13 to 18 and a lot of age specific variation in PEFR values is expected. Reference standards for pulmonary function that are reported for Indian children mainly from Northern, Western and Southern region of the Country (9-12). There is no separate data for adolescent as in most of the study children and adolescents are considering under children group. There is paucity of data on PEFR of adolescent of India. The reference standard of other country cannot be extrapolated to Indian adolescent as the environment; customs, traditions and life style are all together different in this part of the country. The present study was designed to measure the PEFR of adolescent boys and girls of Hooghly district of West Bengal state and to derive prediction formula for this population. 


\section{Material and Methods}

Study subject: The present study was conducted among normal healthy school children of 13-18 years studying in various schools in Hooghly district during their school hours. The prior written permission of school authority was taken. Written consent from the parents of the students experimented in the study was obtained. 1288 students (767boys and 521 girls) were included in this study. The subjects of this study were chosen at random irrespective of socioeconomic status and religion so that reflection of an overall picture of PEFR status of study region could be achieved. Six schools were selected for this study. We excluded the students who did not complete the lung function test correctly, who reported being active smoker, who had allergic diseases and who had been hospitalized with respiratory or cardio vascular complaint. A total of 1400 were selected first, out of which 112 children were debarred either due to exclusion criteria or due to unsatisfactory expiratory effort during the procedure.

Measurement of PEFR: The Wright's Peak Flow Meter (Air Med, UK) has been used. The dial range is 60-800 L/min. All incorporated children were tested in a standing position. Before testing, the modus operandi was explained and demonstrated to each child until full familiarity was achieved. Each child was asked to take deep breath and then blow into peak flow meter as hard and fast as he/she could. Three trials were given and best of the three was chosen for analysis. The same peak flow meter was used through out this study.

Measurement of body weight: Body weight was measured using bathroom scale accurate to $0.5 \mathrm{~kg}$. The scale was kept on a flat surface and adjusted with ' 0 ' mark. Now the subject was requested to step on it in bare feet. Weights were taken in light cloth. Weight was recorded to the nearest $0.5 \mathrm{~kg}$.

Measurement of body height: Height was measured using anthropometric rod. Height of the subject was recorded without footwear and expressed to the nearest $0.1 \mathrm{~cm}$.

Measurement of body mass index (BMI): BMI was calculated from the height and weight using following equation: BMI $\left(\mathrm{kg} / \mathrm{m}^{2}\right)=$ weight $(\mathrm{kg}) /$ height $^{2}(\mathrm{~m})$ formula (13)

Measurement of body surface area (BSA): BSA was calculated from height and weight using Mosteller

Statistical analysis: Data obtained from the study were given as mean \pm SD. The statistical significance was determined by student's $t$ test. Two tailed $p$ values were used throughout and $p$ value less than 0.01 were judged as statistically significant. Pearson correlation was used to find the significant relationship between PEFR and anthropometric parameters. Prediction equations by regression analysis were carried out.

\section{Results}

The present study was conducted among 1288 normal healthy school children (boys 767, girls 521) 1318 years age in Hooghly, West Bengal. Table 1 shows age and gender distribution of study subject. There are $35 \%$ girls and $65 \%$ boys.

TABLE 1: Age and gender distribution of subject studied

\begin{tabular}{|l|l|l|l|l|l|l|}
\hline \multirow{2}{*}{$\begin{array}{l}\text { Age } \\
(\text { yrs })\end{array}$} & \multicolumn{1}{|c|}{ Boys } & \multicolumn{2}{c|}{ Girls } & \multicolumn{2}{c|}{ Total } \\
\cline { 2 - 7 } & Number & $\%$ & Number & $\%$ & Number & $\%$ \\
\hline 13 & 235 & 30.6 & 151 & 29.0 & 386 & 30 \\
\hline 14 & 178 & 23.2 & 141 & 27.1 & 319 & 24.8 \\
\hline 15 & 117 & 15.3 & 85 & 16.3 & 202 & 15.7 \\
\hline 17 & 74 & 9.6 & 28 & 5.4 & 102 & 7.9 \\
\hline 18 & 70 & 9.1 & 51 & 9.8 & 121 & 9.4 \\
\hline total & 767 & 12.1 & 65 & 12.5 & 158 & 12.3 \\
\hline
\end{tabular}

In all study age group boys show significantly higher PEFR than female (table-2). Mean PEFR of boys is also significantly higher than girls in respect to height (table-3), weight (table) as well as BSA (table5).

TABLE 2: Comparison of Mean PEFR of adolescent boys and girls according to age

\begin{tabular}{|l|l|l|l|}
\hline \multirow{2}{*}{ Age (years) } & \multicolumn{2}{|c|}{ PEFR $(1 / \mathrm{min})$} & \multirow{2}{*}{ P value } \\
\cline { 2 - 3 } & \multicolumn{1}{|c|}{ Boys } & Girls & \\
\hline 13 & $360.55 \pm 48.29$ & $281.32 \pm 46.66$ & $<0.001$ \\
\hline 14 & $392.36 \pm 65.78$ & $295.74 \pm 38.58$ & $<0.001$ \\
\hline 15 & $424.87 \pm 81.60$ & $301.05 \pm 50.83$ & $<0.001$ \\
\hline 16 & $443.33 \pm 68.94$ & $331.43 \pm 68.08$ & $<0.001$ \\
\hline 17 & $485.71 \pm 67.73$ & $369.21 \pm 46.68$ & $<0.001$ \\
\hline 18 & $514.00 \pm 60.42$ & $375.38 \pm 32.45$ & $<0.001$ \\
\hline
\end{tabular}

Data represent mean $\pm \mathrm{SD}$ 
Peak Expiratory Flow Rate in Respect to Anthropometric Parameters of Adolescent Boys and Girls

TABLE 3: Comparison of Mean PEFR of adolescent boys and girls according to height

\begin{tabular}{|l|l|l|l|}
\hline \multirow{2}{*}{ Height $(\mathrm{cm})$} & \multicolumn{2}{|c|}{ PEFR $(1 / \mathrm{min})$} & \multirow{2}{*}{ P value } \\
\cline { 2 - 4 } & Boys & Girls & \\
\hline$<130$ & $300.00 \pm 34.64$ & $300.00 \pm 28.30$ & $>0.001$ \\
\hline $131-140$ & $327.60 \pm 33.14$ & $306.47 \pm 41.11$ & $<0.001$ \\
\hline $141-150$ & $347.44 \pm 41.12$ & $303.89 \pm 50.46$ & $<0.001$ \\
\hline $151-160$ & $404.31 \pm 66.59$ & $319.47 \pm 61.90$ & $<0.001$ \\
\hline $161-170$ & $468.11 \pm 73.86$ & $358.07 \pm 60.10$ & ----- \\
\hline $170-180$ & $499.15 \pm 67.88$ & ----- & \\
\hline
\end{tabular}

Data represent mean $\pm \mathrm{SD}$

TABLE 4: Comparison of Mean PEFR of adolescent boys and girls according to weight

\begin{tabular}{|l|l|l|l|}
\hline \multirow{2}{*}{ Weight $(\mathrm{kg})$} & \multicolumn{2}{|c|}{ PEFR $(1 / \mathrm{min})$} & \multirow{2}{*}{ P value } \\
\cline { 2 - 4 } & Boys & Girls & $>0.001$ \\
\hline$\leq 30$ & $326.14 \pm 39.85$ & $299.43 \pm 44.19$ & $<0.001$ \\
\hline $31-40$ & $373.54 \pm 56.18$ & $296.45 \pm 47.52$ & $<0.001$ \\
\hline $41-50$ & $419.39 \pm 74.55$ & $314.51 \pm 58.73$ & $<0.001$ \\
\hline $51-60$ & $466.00 \pm 74.97$ & $347.23 \pm 57.31$ & $<0.001$ \\
\hline $61-70$ & $485.10 \pm 71.06$ & $353.12 \pm 61.89$ & ----- \\
\hline$>70$ & $499.70 \pm 83.00$ & ------ & \\
\hline
\end{tabular}

Data represent mean \pm SD

TABLE 5: Comparison of Mean PEFR of adolescent boys and girls according to body surface area

\begin{tabular}{|l|l|l|c|}
\hline \multirow{2}{*}{ BSA $\left(\mathrm{m}^{2}\right)$} & \multicolumn{1}{|c|}{ PEFR $(1 / \mathrm{min})$} & P value \\
\cline { 2 - 4 } & \multicolumn{1}{|c|}{ Boys } & Girls & \\
\hline$>1.10$ & $325.76 \pm 34.00$ & $294.75 \pm 39.05$ & $>0.001$ \\
\hline $1.11-1.20$ & $347.88 \pm 43.51$ & $295.75 \pm 43.91$ & $<0.001$ \\
\hline $1.21-1.30$ & $373.30 \pm 45.02$ & $303.08 \pm 50.88$ & $<0.001$ \\
\hline $1.31-1.40$ & $408.79 \pm 67.60$ & $308.88 \pm 56.66$ & $<0.001$ \\
\hline $1.51-1.50$ & $425.27 \pm 70.88$ & $351.72 \pm 63.85$ & $<0.001$ \\
\hline $1.61-1.70$ & $460.70 \pm 72.38$ & $344.69 \pm 55.27$ & $<0.001$ \\
\hline $1.71-1.80$ & $487.06 \pm 78.05$ & $345.41 \pm 60.57$ & $<0.001$ \\
\hline
\end{tabular}

Data represent mean \pm

Correlation coefficient between anthropometric variables and PEFR of school children was shown in table 6. Five anthropometric variables viz age, height, weight, BMI and BSA were correlated with PEFR. Highest correlation was found with age for boys and girls where as lowest with BMI for boys height for girls.

TABLE 6: Pearson correlation of PEFR and anthropometric parameters

\begin{tabular}{|l|l|l|l|l|}
\hline \multirow{2}{*}{ Pair } & \multicolumn{2}{|c|}{ Boys } & \multicolumn{2}{c|}{ Girls } \\
\cline { 2 - 5 } & r value value & r value & p value \\
\hline PEFR vs Age & 0.650 & $<0.001$ & 0.601 & $<0.001$ \\
\hline PEFR vs Height & 0.642 & $<0.001$ & 0.244 & $<0.001$ \\
\hline PEFR vs Weight & 0.586 & $<0.001$ & 0.308 & $<0.001$ \\
\hline PEFR vs BMI & 0.400 & $<0.001$ & 0.254 & $<0.001$ \\
\hline PEFR vs BSA & 0.627 & $<0.001$ & 0.314 & $<0.001$ \\
\hline
\end{tabular}

Simple regression analysis was done for PEFR. Table 7 represents the simple regression equations for prediction of PEFR on the basis of anthropometric variables those were significantly correlated with PEFR.

TABLE 7: Simple regression equations on the basis of anthropometric parameters for predicting PEFR

\begin{tabular}{|c|c|c|}
\hline S1 no & Boys & Girls \\
\hline 1 & $\operatorname{PEFR}(1 / \mathrm{min})=(30.913 *$ age in year $)-40.813$ & PEFR $(1 / \mathrm{min})=(19.807 *$ age in year $)+20.568$ \\
\hline 2 & $\operatorname{PEFR}(1 / \mathrm{min})=(5.367 *$ height in $\mathrm{cm})-427.56$ & $\operatorname{PEFR}(1 / \min )=(2.199 *$ height in $\mathrm{cm})-16.634$ \\
\hline 3 & $\operatorname{PEFR}(1 / \mathrm{min})=(4.113 *$ weight in $\mathrm{kg})+266.066$ & $\operatorname{PEFR}(1 / \mathrm{min})=(1.838 *$ weight in $\mathrm{kg})+233.763$ \\
\hline 4 & $\operatorname{PEFR}(1 / \mathrm{min})=(241.526 * \mathrm{BSA}$ in $\mathrm{sq} \mathrm{m})+74.940$ & $\operatorname{PEFR}(1 / \mathrm{min})=(108.533 * \mathrm{BSA}$ in $\mathrm{sq} \mathrm{m})+168.228$ \\
\hline 5 & $\operatorname{PEFR}(1 / \mathrm{min})=\left(10.686 * \mathrm{BMI}\right.$ in $\left.\mathrm{kg} / \mathrm{m}^{2}\right)+219.214$ & $\operatorname{PEFR}(1 / \mathrm{min})=\left(4.210 * \mathrm{BMI}\right.$ in $\left.\mathrm{kg} / \mathrm{m}^{2}\right)+232.793$ \\
\hline
\end{tabular}

Multiple regression analysis was also done to evaluate prediction equations for PEFR. Multiple regression equation for PEFR on the basis of two variables, age and height; age and weight and age and BSA were represented in table 8 . 
TABLE 8: Multiple regression equations for predicting PEFR of adolescent

\begin{tabular}{|l|l|l|}
\hline Subject & \multicolumn{1}{|c|}{ Equation } & R \\
\hline \multirow{5}{*}{ Boys } & PEFR $(1 / \mathrm{min})=(18.584 *$ age in year $)+(3.364 *$ height in $\mathrm{cm})-387.584$ & 0.7627 \\
\cline { 2 - 4 } & PEFR $(1 / \mathrm{min})=(21.812 *$ age in year $)+(2.169 *$ weight in $\mathrm{kg})-6.671$ & 0.7205 \\
\cline { 2 - 4 } & PEFR $(1 / \mathrm{min})=(19.888 *$ age in year $)+(144.256 * \mathrm{BSA})-81.765$ & 0.7498 \\
\hline \multirow{5}{*}{ Girls } & PEFR $(1 / \mathrm{min})=(19.964 *$ age in year $)-(0.0988 *$ height in $\mathrm{cm})+32.455$ & 0.6006 \\
\cline { 2 - 4 } & PEFR $(1 / \mathrm{min})=(20.580 *$ age in year $)-(0.2486 *$ weight in $\mathrm{kg})+19.248-6.671$ & 0.5997 \\
\cline { 2 - 4 } & PEFR $(1 / \mathrm{min})=(20.568 *$ age in year $)-(13.969 * \mathrm{BSA})-27.333$ & 0.5997 \\
\hline
\end{tabular}

\section{Discussion}

PEFR is a simple and reliable way to supervise the harshness of bronchial asthma and assessing the response to its treatment. It is dependent upon various factors including airway resistance, effort of voluntary expiratory muscles. Physicians prefer a common international reference for obtaining normal values of different parameters but it has been shown that PEFR values vary with racial, environment, genetic feature, lifestyle and geographical distribution. Thus it would be more appropriate for each country for its own regional reference values. The aim of this study was to establish normal value of PEFR of healthy adolescent of West Bengal, India, so that local reference standards would be available when this measurement is used for the assessment of asthmatic children.

PEFR values increased in linear relation to age, height, weight, BMI and BSA. Correlation coefficient of PEFR with age, height, weight, and BSA are significant but insignificant with BMI. Highest correlation was noted for age in boys and girls. Age, height, weight and BSA have all been used either alone or in combination to predict PEFR in various studies (14-16). Like many other Indian studies, we evaluated simple regression equations on the basis of age, height, weight and BSA. Multiple regression equations were also evaluated on the basis of age - height, age- weight, and age - BSA.

We admit that EFV1 is a better indicator of airway obstruction in respect to PEFR. However, the ease of measuring the PEFR with an inexpensive portable instrument has made it preferable over FEV1. Moreover the previous studies carried out worldwide suggest a significant positive correlation between FEV1 and PEFR (17-18). Thus PEFR may also be considered as a suitable alternative measure of airway obstruction in instances where FEV1 is unavailable. Our predicted equations for PEFR can be used to evaluate the pulmonary function of patients who are in same age group suffering from bronchial asthma.

\section{Conclusion:}

In present study age, height, weight and BSA have been used separately for evaluation of simple regression equation for PEFR. Two anthropometric parameters viz. age and height; age and weight; and age and both BSA have been used for multiple regression equations for PEFR in Eastern Indian Bengali adolescent. In view of the large sample size in the age range of 13-18 years the equations of the present study would be useful for both physiologist and clinicians to evaluate bronchial asthma of adolescent of eastern region of India.

\section{Acknowledgements}

The authors thankfully acknowledge the cooperation rendered by school authorities, school children and their parents. Their kind cooperation in this investigation is highly cherished from the core of our heart. The authors thank Parthiba Pramanik and Sunirmal Bhattacharya for their active participation in the preparation of manuscript.

\section{References}

[1]. Saxena Y, Purwar B, Upmanyu R. Adiposity: determinant of peak expiratory flow rate in young Indian adults male. Indian j Chest Dis Allied Sci. 2011; 53: 29-33.

[2]. Wright BM, McKerrow CB. Maximum forced expiratory flow as a measure of ventilatory capacity. Br Med J. $1959 ; 2: 1041-1047$.

[3]. Jain S. K., Kumar R., Sharma D. A. (1983): Peak expiratory flow rates in healthy Indian adults: a statistical evaluation. Lung India. 3: 88-91.

[4]. Pagadpally S. Factors affecting peak expiratory flow rate and drive predictive equation in children of 6-12 years of age of karaikal. $\mathrm{J}$ Evolution Med Dental Sci. 2013, 2: 557-571.

[5]. Chinn S, Jarvis D, Burney P. Relation of bronchial responsiveness to BMI in the ECRHS. Thorax. 2002; 57: 1028-1033.

[6]. Mitchell E. A. (1985): International trends in hospital admission rates for asthma. Arch. Dis. Child. 60: 676-78.

[7]. Mondal K.B., Sen S., Mahapatra N. C., Banerjee A, Ray A, Chakravorti S. (2011): A study of peak expiratory flow rate in 6-12 age group in relation to height in eastern India. The child \& Newborn. 15: 8-13.

[8]. Malik SK, Jindal SK, Sharma PK, Banga N. Peak expiratory flow rate of healthy school girls from Punjab. 1982; 18: 161-164)

[9]. Paramesh H. (2003): Normal peak expiratory flow rate in urban and rural children. Indian J Pediatr. 70: $375-377$.

[10]. Malik S. K., Jindal S. K. (1985): Pulmonary function tests in healthy children. Indian Pediatr. 22: 677-681

[11]. Chowgule RV, Shetye VM, Parmar JR. Lung function test in normal Indian Children. Indian Pediatric. 1995, 32: 185-191.

[12]. Sharma M, Sharma RB, Choudhary R. Peak expiratory flow rates in children of western Rajasthan 7-14 years of age. Pak J Physiol. $2012,8: 45-48$ 
[13]. Mosteller R. D. (1987): Simplified calculation of body surface area. New Eng J Med. 317: 1098

[14]. Mittal S., Gupta S., Kumar A., Singh K. D. (2013): Regression equations for peak expiratory flow in healthy children aged 7 to 14 years from Punjab, India. Lung India. 30; 183-186.

[15]. Pande I. N., Mohan A., khilnani S., khilnani G. C. (1997): peak expiratory flow rate of school going children. Indian J chest dis allied Sci. 39; 87-95.

[16]. Nair R. H., Kesavchandran C., Sanil R., Sreekumar R., Shashidhar S. (1997): Prediction equation for lung functions in South Indian children. Indian J Physiol Pharmacol. 41: 390-396.

[17]. Gibson PG. Monitoring the patient with asthma; an evidence based approach. J allergy clin Immunol. 2000; 106: 17-26.

[18]. Slieker MG, van der Ent CK. The diagnostic and screening capacities of peak expiratory flow measurement in the assessment of airway obstruction and bronchiodilator response in children with asthma. Monaldi Arch Chest Dis. 2003; 59: 155-159. 